\title{
Pituitary hyperplasia due to Himalayan endemic hypothyroidism
}

\author{
Shabal Sapkota ${ }^{1}$, Sulav Sapkota ${ }^{2}$, and Mitesh Karn ${ }^{1}$ \\ ${ }^{1}$ Gandaki Medical College Teaching Hospital and Research Center Pvt Ltd \\ ${ }^{2}$ Birat Medical College
}

August 23, 2020

\begin{abstract}
Pituitary hyperplasia due to endemic hypothyroidism is very rare and should be considered in the differential diagnosis of pituitary neoplasm, especially if the patient hails from endemic iodine deficient regions such as the Himalayas. Establishing correct diagnosis may save the patient of any unnecessary neurosurgical intervention.
\end{abstract}

\section{Title: Pituitary hyperplasia due to Himalayan endemic hypothy- roidism}

Authors: Shabal Sapkota,MD, FWFNS ${ }^{1}$

Sulav Sapkota $\mathrm{MD}^{2}$, Mitesh Karn ${ }^{3}$

Affiliations:

${ }^{1}$ Department of Neurosurgery, Gandaki Medical College Teaching Hospital and Research Center, Pokhara, Nepal. Email: shabalsapkota@gmail.com

${ }^{2}$ Department of Medical Oncology, Birat Medical College, Biratnagar, Nepal, Email: Sapsalvage7@yahoo.com

${ }^{3}$ School of Medicine, Gandaki Medical College Teaching Hospital and Research Center, Pokhara, Nepal. Email: rikkymikky@gmail.com

Corresponding Author's name and current institution: Dr. Shabal Sapkota, Department of Neurosurgery, Gandaki Medical College Teaching Hospital and Research Center, Pokhara, Nepal. Email: shabalsapkota@gmail.com

\section{Abstract :}

Pituitary hyperplasia due to endemic hypothyroidism is very rare and should be considered in the differential diagnosis of pituitary neoplasm, especially if the patient hails from endemic iodine deficient regions such as the Himalayas. Establishing correct diagnosis may save the patient of any unnecessary neurosurgical intervention.

KEYWORDS : endemic goiter; hypothyroidism; pituitary hyperplasia; case report

\section{Key Clinical Message}


Pituitary hyperplasia due to endemic hypothyroidism should be considered as differential diagnosis of pituitary neoplasm. Thorough endocrinological evaluation should be done to avoid unnecessary surgery for lesion that can be treated medically.

\section{INTRODUCTION}

Pituitary hyperplasia can occur due to variety of physiological and pathological conditions, including pregnancy, puberty and endocrine abnormalities. ${ }^{1}$ Pituitary hyperplasia following primary hypothyroidism was first reported in 1851 by Niepce who described the enlargement of sella turcica in cretins with hypothyroidism. ${ }^{2}$ Despite traditionally thought as being uncommon ${ }^{3}$, this condition has been well documented in the literature ever since. However, pituitary hyperplasia following primary hypothyroidism is rarely encountered in the pediatric population. ${ }^{4}$

We report a case of 12 years old girl who was referred to the neurosurgery department of our teaching hospital for surgical evaluation of a suspected pituitary neoplastic lesion which was later found out to be pituitary hyperplasia due to endemic primary hypothyroidism.

\section{CASE REPORT}

History: Our patient is a 12 years old girl, hailing from a Himalayan district of Nepal. She presented with complaints of headache and fatigue for the last 6 months to a peripheral district hospital. CT scans carried out at that center showed a pituitary mass lesion suggestive of pituitary neoplasm. Due to unavailability of surgical care facilities at that hospital, she was referred to our hospital for neurosurgical evaluation of her condition. The patient was born at term, at home and was reportedly well since birth. She and her parents denied any family history of thyroid and autoimmune disorders. She denied having had menarche, hair loss, constipation and visual impairment. She denied smoking, alcohol consumption and illicit drug use.

Examination: On physical examination, our patient had a height of $129 \mathrm{~cm}\left(<3^{\text {rd }}\right.$ percentile), a weight of $54 \mathrm{~kg}\left(>75^{\text {th }}\right.$ percentile) and a BMI of $32.4 \mathrm{~kg} / \mathrm{m}^{2}$. At the time of initial presentation to our facility, she had a blood pressure of $104 / 72 \mathrm{mmHg}$, a regular heart rate at 63 beats per minute and a respiratory rate of 15 per minute. She had a coarse and dry skin. She looked obese and short for her age. Neurologic and visual field examination revealed no abnormalities. Thyromegaly was grossly evident. Neck examination revealed bilaterally enlarged and palpable thyroid lobes. She was a Tanner Stage I for breasts and pubic hair. External genital organs were normally developed for age.

Initial laboratory evaluation (Table 1) revealed a TSH (Thyroid-stimulating Hormone) of $149.6 \mu \mathrm{IU} / \mathrm{ml}$, a T4 (Thyroxine) of $0.2 \mu \mathrm{g} / \mathrm{dl}$, T3 (Triiodithyronine) $11 \mathrm{ng} / \mathrm{dl}$, GH (Growth Hormone) $4.7 \mathrm{ng} / \mathrm{ml}, \mathrm{LH}$ (Luteinizing Hormone) $0.26 \mathrm{mIU} / \mathrm{ml}$, FSH (Follicle-stimulating Hormone) $0.78 \mathrm{mIU} / \mathrm{ml}$ and serum Prolactin $59.2 \mathrm{ng} / \mathrm{ml}$. Cortisol and ACTH (Adrenocorticotrophic Hormone) levels were within normal range. She had a hemoglobin level of $9.1 \mathrm{~g} / \mathrm{dl}$, a random blood glucose of $80 \mathrm{mg} / \mathrm{dl}$, a LDL-C (Low Density Lipoprotein-C) level of $156 \mathrm{mg} / \mathrm{dl}$ and a Triglyceride level of $193 \mathrm{mg} / \mathrm{dl}$. Urinary iodine was found out to be $12 \mathrm{mcg} / \mathrm{L}$. Antibody tests for thyroid autoantibodies were negative. CT scan of her head (Figure 1) showed a $9 \mathrm{~mm}$ symmetrical, homogeneously enhanced, round and hyper dense mass in the widened pituitary fossa suggestive of pituitary adenoma.

Ultrasound guided FNAC (Fine Needle Aspiration Cytology) of the thyroid showed cells arranged in sheets with scanty cytoplasm, with oval to round nucleus and numerous bare nuclei against a thin colloidal background, features suggestive of endemic goiter.

Though the patient was initially evaluated for surgical resection of the mass lesion, prompt identification of her condition prevented any unnecessary surgical intervention. She was treated with $50 \mathrm{mcg}$ of Levothyroxine tablets and was advised for iodine fortified salt intake every day. After 2 months of treatment, repeat thyroid function tests showed significant improvement. Lab reports showed a serum TSH of $4.7 \mu \mathrm{IU} / \mathrm{ml}(\mathrm{N}=0.4$ $6.1 \mu \mathrm{IU} / \mathrm{ml})$, FT4 of $1 \mathrm{ng} / \mathrm{dl}(\mathrm{N}=0.8-2 \mathrm{ng} / \mathrm{ml})$, FT3 of $2.8 \mathrm{pg} / \mathrm{dl}(\mathrm{N}=1.4-4.2 \mathrm{pg} / \mathrm{dl}), \mathrm{GH}$ of $8.7 \mathrm{ng} / \mathrm{ml}$ and serum Prolactin normalized to $7.5 \mathrm{ng} / \mathrm{ml}(\mathrm{N} 1.2-15.5 \mathrm{ng} / \mathrm{ml}$ ). Follow up CT scan after 4 months (Figure 2) showed regression of the pituitary mass. She had reduction of her goiter and her height increased to $157 \mathrm{~cm}\left(>50^{\text {th }}\right.$ 
Percentile) after 1 year. All her symptoms resolved. She was counselled to consume iodized salt and sent back home.

\section{DISCUSSION}

Iodine deficiency is the most common cause of hypothyroidism worldwide. ${ }^{5}$ This is more common in Himalayan country like Nepal, where it is endemically present. ${ }^{6,7}$ This is the first reported case of pituitary hyperplasia following primary hypothyroidism due to endemic iodine deficiency.

Primary hypothyroidism leads to pituitary hyperplasia due to loss of feedback inhibition from circulating thyroid hormones thyroxine (T4) and triiodothyronine (T3) on the hypothalamus, leading to increased production of Thyrotropin Releasing Hormone (TRH) and consequently increased activity of thyrotropes. ${ }^{8}$ With acute development of hypothyroidism, rapid progression of hyperplasia of the anterior pituitary may occur in as less as 5 weeks. ${ }^{9}$ Serum prolactin level is elevated in majority of patients with hypothyroidism and this increase is due to TRH. ${ }^{10}$ Additionally, the response of prolactin to TRH is exaggerated in hypothyroid state $^{11}$ and this fact is supported by pituitary lactotroph hyperplasia seen in histology specimens of hypothyroid patients. ${ }^{12}$ Growth hormone levels are reduced in children with pituitary hyperplasia secondary to primary hypothyroidism ${ }^{13,14}$ presumably due to compression of pituitary stalk and infundibulum ${ }^{15}$ or trans differentiation of somatotropes to thyrotropes. ${ }^{16}$ It may also be due to reduced thyroxine levels, which has stimulating effects on growth hormone synthesis. ${ }^{17}$

In pediatric population, pituitary hyperplasia following primary hypothyroidism presents predominantly with features of hypothyroidism such as short stature, fatigue, myxedema and of increased prolactin such as menstrual disorders and galactorrhea. ${ }^{18}$ Visual impairment and neurological abnormalities are rare in children. ${ }^{18}$ Our case also demonstrated similar findings but despite increased prolactin levels, we did not observe features of hyperprolactinemia.

CT and MRI, with and without contrast, have been used for diagnosing pituitary hyperplasia since decades. MRI usually demonstrates homogenous, isodense, diffuse and symmetrical enlargement of pituitary gland. ${ }^{14,19} \mathrm{CT}$ reveals a round, isodense mass with homogenous enhancement in midline sellar region. ${ }^{20,21}$ The findings in our case is similar to what is described in the literature. Though recommended, our patient didn't undergo MRI citing financial constraints. CT scans are still used in developing countries for evaluation of pituitary mass lesions owing to its accessibility and affordability over MRI.

There are various causes of sellar masses in children, including craniopharyngeal neoplasms, intracranial germ cell tumors, pituitary adenoma and pituitary hyperplasia. ${ }^{4,18}$ Of these conditions, it may be very difficult to distinguish pituitary adenoma from hyperplasia as they share similar radiological and clinical features. Though pituitary adenoma following primary hypothyroidism has also been reported ${ }^{22}$, it is very rare. Thyrotropin producing pituitary adenoma may also be a possibility given the pituitary mass and increased TSH level, but these tumors are exceedingly rare, accounting only $0.5 \%$ of all pituitary adenomas. ${ }^{23}$ It is imperative to distinguish pituitary adenoma from pituitary hyperplasia as the therapeutic options are very different for their management: surgery for adenoma and thyroid replacement for hyperplasia secondary to hypothyroidism. If a proper diagnosis is reached, the patient can be saved of the consequences of unwanted surgical intervention.

It is also necessary in children with pituitary hyperplasia to distinguish physiological from pathological hyperplasia. Though the gland increases considerably during puberty, reportedly up to $8 \mathrm{~mm}^{24}$, there are no symptoms of disease states since it is entirely physiologic. Pathological hyperplasia occurs in response to endocrine disorders such as hypothyroidism. ${ }^{25}$ This condition presents with clinical features and laboratory results consistent with the underlying pathological state. In our case as well, there were clear features of hypothyroidism.

There are many causes of hypothyroidism leading to pituitary hyperplasia in children, the most common being Hashimoto's thyroiditis. ${ }^{26}$ Other common causes include subtotal thyroidectomy, radioactive iodine therapy and drugs like interferon and thionamides. Our patient was not on any of these medications and was negative 
for antithyroid antibodies. Based on the clinical features, laboratory findings, cytology report and the high prevalence of endemic goiter in her community, a diagnosis of iodine deficiency hypothyroidism leading to pituitary hyperplasia was established. For people hailing from Himalayan region with high prevalence of endemic goiter and where iodine fortified salt is not available, hypothyroidism due to iodine deficiency should also be considered as a cause of pituitary hyperplasia.

\section{CONCLUSION}

Pituitary hyperplasia due to hypothyroidism is uncommon is children. For patients presenting with pituitary mass on CT scan or MRI with clinical features suggestive of hypothyroidism, a thorough endocrine evaluation must be carried out before considering surgical resection so that this reversible condition would not be mistaken for adenoma and subsequent surgeries could be avoided. For patient from Himalayan and other endemic regions, iodine deficiency hypothyroidism must also be considered along with other common causes. This should be treated with thyroid hormone replacement and consumption of iodine fortified foods.

List of abbreviation:

$\mathrm{TSH}=$ Thyroid Stimulating Hormone

$\mathrm{T} 4=$ Thyroxine

$\mathrm{T} 3=$ Triiodothyronine

$\mathrm{GH}=$ Growth Hormone

$\mathrm{LH}=$ Luteinizing Hormone

$\mathrm{FSH}=$ Follicle Stimulating Hormone

LDL $=$ Low Density Lipoprotein

FT3= Free Triiodothyronine

FT4= Free Thyroxine

Declarations:

ETHICAL APPROVAL: Not applicable

CONSENT FOR PUBLICATION: Written informed consent was obtained from the both the patient and her parents for publication of this case report and any accompanying images.

CONFLICT OF INTEREST: None.

FUNDING: None

AUTHOR CONTRIBUTIONS: Concept by SS; design, literature review and write up by SS and MK; final manuscript seen and approved by SS and MK.

ACKNOWLEDGEMENTS: None.

REFERENCES:

1. Shukla P, Bulsara KR, Luthra P. Pituitary Hyperplasia in Severe Primary Hypothyroidism: A Case Report and Review of the Literature. Case Rep Endocrinol . 2019;2019. doi:10.1155/2019/2012546

2. Niepce B. Traite du goitre et du cretinism. Bailliers Paris . 1851;(30).

3. Dutta D, Maisnam I, Ghosh S, Mukhopadhyay P, Mukhopadhyay S, Chowdhury S. Panhypopituitarism with empty sella a sequel of pituitary hyperplasia due to chronic primary hypothyroidism. Indian $J$ Endocrinol Metab . 2012;16(Suppl 2):S282-4. doi:10.4103/2230-8210.104060 
4. CY L, HH H, HY L, ST L. Rapid progression of hypothyroidism-related pituitary hyperplasia. J Neurosurg Pediatr . 2008;2(3). doi:10.3171/PED/2008/2/9/212

5. Vanderpump MPJ. The epidemiology of thyroid disease. doi:10.1093/bmb/ldr030

6. Pearce EN, Andersson M, Zimmermann MB. Global iodine nutrition: Where do we stand in 2013 ? Thyroid . 2013;23(5):523-528. doi:10.1089/thy.2013.0128

7. Khatiwada S, Gelal B, Gautam S, Lamsal M, Baral N. Iodine Status among School Children of remote Hilly regions of Nepal. Indian Pediatr. 2015;52(5):436-437. Accessed August 4, 2020. https://pubmed.ncbi.nlm.nih.gov/26061936/

8. Hu YY, Li GM, Hu WW, Wang Y. Characteristics of girls with pituitary hyperplasia and sexual precocity secondary to primary hypothyroidism. Acta Paediatr Int J Paediatr . 2014;103(1). doi:10.1111/apa.12444

9. Shimono T, Hatabu H, Kasagi K, et al. Rapid progression of pituitary hyperplasia in humans with primary hypothyroidism: Demonstration with MR imaging. Radiology . 1999;213(2):383-388. doi:10.1148/radiology.213.2.r99nv02383

10. Honbo KS, Van Herle AJ, Kellett KA. Serum prolactin levels in untreated primary hypothyroldism. $A m$ J Med . 1978;64(5):782-787. doi:10.1016/0002-9343(78)90517-X

11. Snyder PJ, Jacobs LS, Utiger RD, Daughaday WH. Thyroid hormone inhibition of the prolactin response to thyrotropin releasing hormone.J Clin Invest . 1973;52(9):2324-2329. doi:10.1172/JCI107421

12. Scheithauer BW, Kovacs K, Randall R V, Ryan N. Pituitary gland in hypothyroidism. Histologic and immunocytologic study. Arch Pathol Lab Med . 1985;109(6):499-504. Accessed August 5, 2020. http://www.ncbi.nlm.nih.gov/pubmed/2986571

13. Papakonstantinou O, Bitsori M, Mamoulakis D, Bakantaki A, Papadaki E, Gourtsoyiannis N. MR imaging of pituitary hyperplasia in a child with growth arrest and primary hypothyroidism. Eur Radiol . 2000;10(3):516-518. doi:10.1007/s003300050087

14. Kocova M, Netkov S, Sukarova-Angelovska E. Pituitary Pseudotumor with Unusual Presentation Reversed Shortly after the Introduction of Thyroxine Replacement Therapy. J Pediatr Endocrinol Metab . 2001;14(9):1665-1669. doi:10.1515/JPEM.2001.14.9.1665

15. Liu M, Hu Y, Li G, Hu W. Low growth hormone levels in short-stature children with pituitary hyperplasia secondary to primary hypothyroidism. Int J Endocrinol . Published online 2015. doi:10.1155/2015/283492

16. Vidal S, Horvath E, Kovacs K, Cohen SM, Lloyd R V., Scheithauer BW. Transdifferentiation of somatotrophs to thyrotrophs in the pituitary of patients with protracted primary hypothyroidism. Virchows Arch . Published online 2000. doi:10.1007/PL00008197

17. Buchanan, CR; Stanhope, R; Adlard P. Gonadotrophin, Growth hormone and Prolactin secretion in chilldren with primary hypothyroidism. Clin Endocrinol (Oxf) . Published online 1988. doi:10.1111/j.13652265.1988.tb02892.x

18. Cao J, Lei T, Chen F, Zhang C, Ma C, Huang H. Primary hypothyroidism in a child leads to pituitary hyperplasia: A case report and literature review. Med (United States) . 2018;97(42). doi:10.1097/MD.0000000000012703

19. Han L, Wang J, Shu K, Lei T. Pituitary tumorous hyperplasia due to primary hypothyroidism. Acta Neurochir (Wien) . 2012;154(8):1489-1492. doi:10.1007/s00701-012-1342-0

20. Nishi Y, Sakano T, Hyodo S, et al. Pituitary abnormalities detected by high resolution computed tomography with thin slices in primary hypothyroidism and Turner syndrome. Eur J Pediatr. Published online 1984. doi:10.1007/BF00442585 
21. Katevuo K, Valimaki M, Ketonen L, Lamberg B -A, Pelkonen R. Computed tomography of the pituitary fossa in primary hypothyroidism. Effect of thyroxine treatment. Clin Endocrinol (Oxf) . 1985;22(5):617-621. doi:10.1111/j.1365-2265.1985.tb02997.x

22. Du J, Ji H, Jin J, Gao S, Yan X, Hu S. Pituitary adenoma secondary to primary hypothyroidism: Two case reports. Med (United States) . 2020;99(8). doi:10.1097/MD.0000000000019222

23. Beck-Peccoz P, Brucker-Davis F, Persani L, Smallridge RC, Weintraub BD. Thyrotropin-secreting pituitary tumors. Endocr Rev . 1996;17(6):610-638. doi:10.1210/er.17.6.610

24. Mazumdar A. Imaging of the pituitary and sella turcica. Expert Rev Anticancer Ther. Published online 2006. doi:10.1586/14737140.6.9s.s15

25. Al-Gahtany M, Horvath E, Kovacs K. Pituitary Hyperplasia.Hormones . 2003;2(3):149-158. doi:10.14310/horm.2002.1195

26. Aijing X, Tang L. Pituitary hyperplasia in children with short stature and primary hypothyroidism. Indian Pediatr . Published online 2010. doi:10.1007/s13312-010-0149-4

Figure Legend:

Figure 1. Initial head CT scan of our patient. We can clearly delineate a round, homogeneously enhanced pituitary mass.

Figure 2. CT Scan Head of Same patient after L-thyroxine therapy and iodine supplementation. After the therapy, the mass regressed completely as shown in the scans.

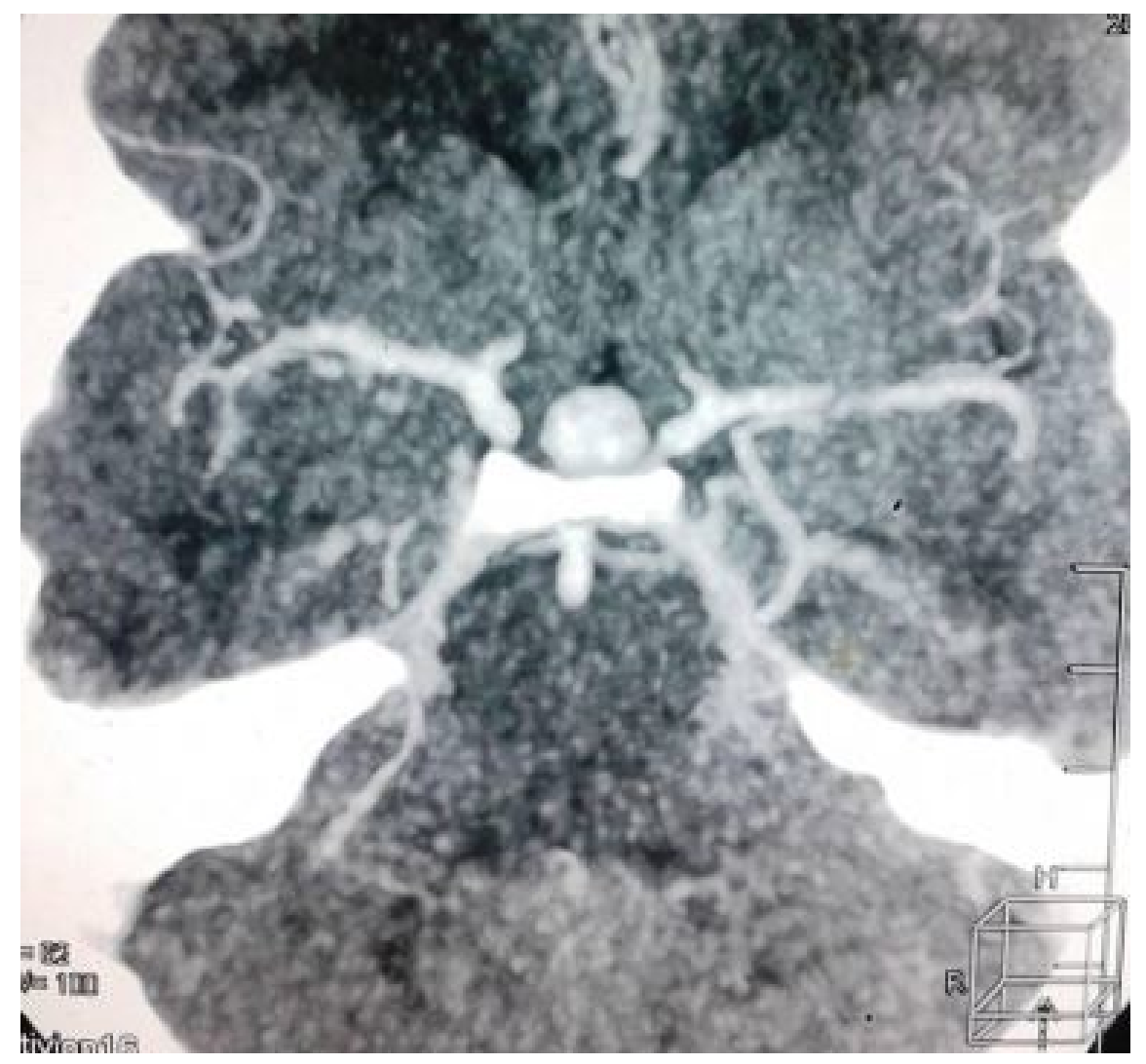




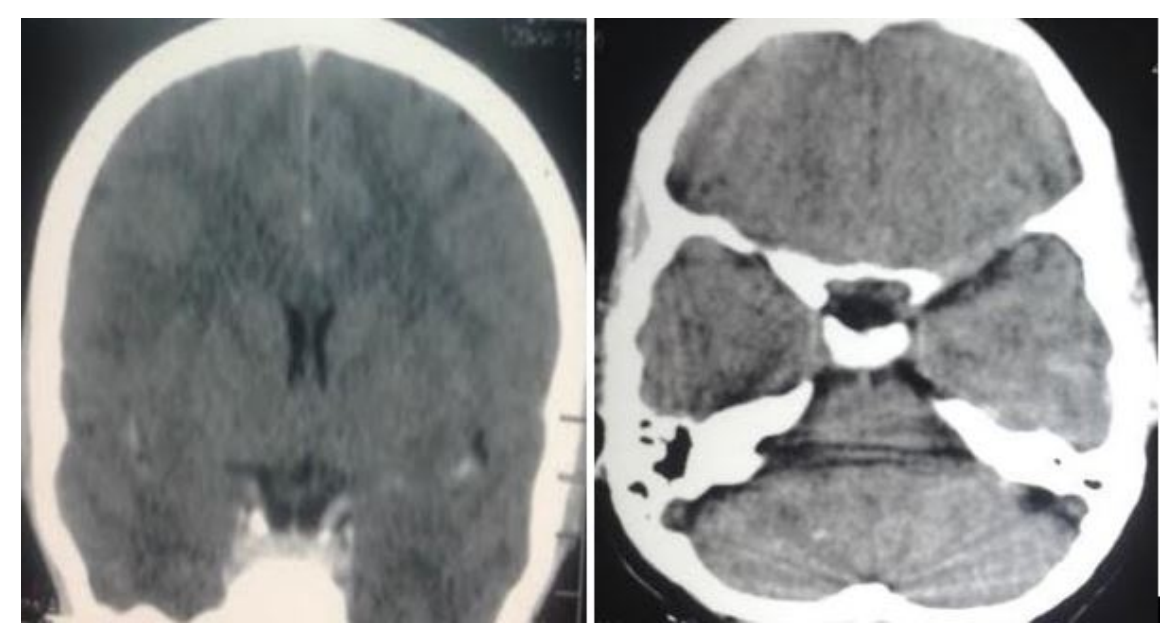

\section{Hosted file}

TABLE 1 .docx available at https://authorea.com/users/353026/articles/477075-pituitaryhyperplasia-due-to-himalayan-endemic-hypothyroidism 